\title{
USING GASEOUS EMISSIONS OF A PROTON ACCELERATOR FACILITY AS TRACER FOR SMALL-SCALE ATMOSPHERIC DISPERSION
}

\author{
G. Butterweck ${ }^{1, *}$, I. Heese ${ }^{1}$, R. Hugi ${ }^{1}$, J. Züllig ${ }^{1}$, H. Hödlmoser ${ }^{1,2}$, E. Hohmann ${ }^{1}$ and S. Mayer ${ }^{1}$ \\ ${ }^{1}$ Paul Scherrer Institute, Villigen, Switzerland \\ ${ }^{2}$ Present address: Helmholtz Zentrum München, Munich, Germany \\ *Corresponding author: gernot.butterweck@psi.ch
}

\begin{abstract}
The gaseous effluents of the proton accelerator facility located in the Western part of the Paul Scherrer Institute, Aargau, Switzerland, contain a mixture of positron emitters $\left(50 \%{ }^{15} \mathrm{O}, 20 \%{ }^{13} \mathrm{~N}\right.$ and $\left.30 \%{ }^{11} \mathrm{C}\right)$. For the experimental verification of a future upgrade of the dispersion model in the complex topography of the Aare valley, a measuring campaign using three continuous gamma-spectrometric measuring stations was launched in 2011. The concept of a modified man-made-gross-count (MMGC) ratio yields a clear signal associated with the positron emitters while minimising the influence of radon progeny rainout events. A dependence of the measured MMGC ratios on the emitted activity and wind direction could be demonstrated using frequency distributions of the modified MMGC ratio measured in 2012 and 2013. A significant fraction of high MMGC-ratio values was found associated with dispersion directions (based on measurements of the wind direction in $70 \mathrm{~m}$ above ground) not towards or even against the direction between stack and measuring station.
\end{abstract}

\section{INTRODUCTION}

The gaseous effluents of the proton accelerator facility located in the Western part of the Paul Scherrer Institute (PSI), Aargau, Switzerland, contain a mixture of positron emitters $\left(50 \%{ }^{15} \mathrm{O}, 20 \%{ }^{13} \mathrm{~N}\right.$ and $\left.30 \%{ }^{11} \mathrm{C}\right)$. The activity concentrations of these radionuclides in the air emitted by the stack with a height of $28 \mathrm{~m}$ are routinely monitored using high-resolution gamma-spectrometry with a time resolution of $10 \mathrm{~min}$ to assure compliance with regulations. The environmental impact of the emissions is calculated using a simple Gaussian plume model.

For the experimental verification of a future upgrade of the dispersion model in the complex topography of the Aare valley, a measuring campaign using three continuous gamma-spectrometric measuring stations was launched in 2011. Thus, measurements of the dispersion of the gaseous emissions are obtained for different weather conditions.

\section{MEASUREMENT STATIONS}

The measuring stations use the $511-\mathrm{keV}$ photon emission of the annihilation of positrons for the detection of the positron emitters. A standard $3^{\prime \prime} \times 3^{\prime \prime} \mathrm{NaI}(\mathrm{Tl})$ photon detector coupled to a tube base/multichannel analyser combination (Canberra Osprey) was mounted in a Styrofoam package inside a weatherproof aluminium box. The measurement is controlled with an energy-efficient personal computer, which has an operating temperature range of -25 to $+70^{\circ} \mathrm{C}$ rendering insulation unnecessary. The photon spectra are measured with a 10 -min counting interval.

\section{Spectrum evaluation}

Figure 1 shows two spectra with main influence from positron emitters and radon progeny. To separate these two cases with a single figure, a method devised for the evaluation of airborne gamma-spectrometric data [man-made-gross-count (MMGC) ratio] was adapted $^{(1)}$. The MMGC-ratio method yields better performance compared with a peak analysis in situations with poor counting statistics. The energy windows used in the MMGC ratio were modified to yield optimum performance in detecting $511-\mathrm{keV}$ radiation. The sum of counts of photons with energies of $<550 \mathrm{keV}$ (vertical dashed line in Figure 1) was divided by the sum of counts from photons with energies of $>550 \mathrm{keV}$ to render the modified MMGC ratio. The modified MMGC ratio shows higher values in the presence of annihilation radiation and lower values in the case of a radon progeny rain-out event.

\section{Location}

The measurement stations are placed to the south, north and east of the emitting stack. Figure 2 shows the locations of the measurement stations, the emitting stack and meteorological equipment on an elevation map of the surroundings of PSI. Paul Scherrer Institute is located in the Aare valley with the Aare River flowing through the Institute from south to north. The wind statistic is dominated by the valley orientation with mainly northern and southern winds (Figure 3 ). The wind directions were measured in $70-\mathrm{m}$ height at the location noted 


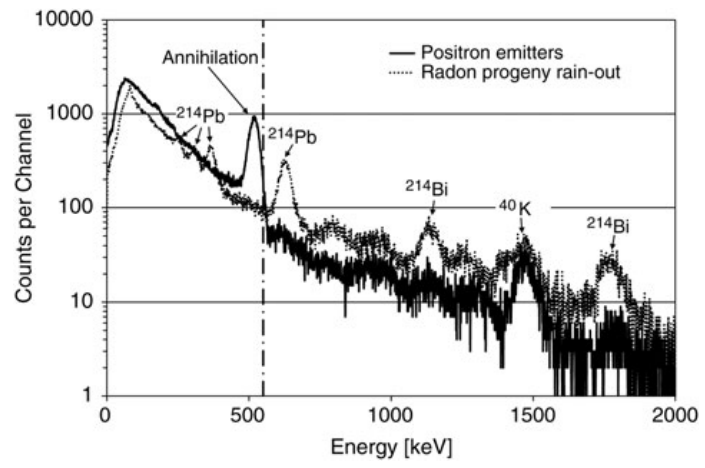

Figure 1. Spectra of a measuring station during events with positron emitters near the station and radon progeny rain-out.

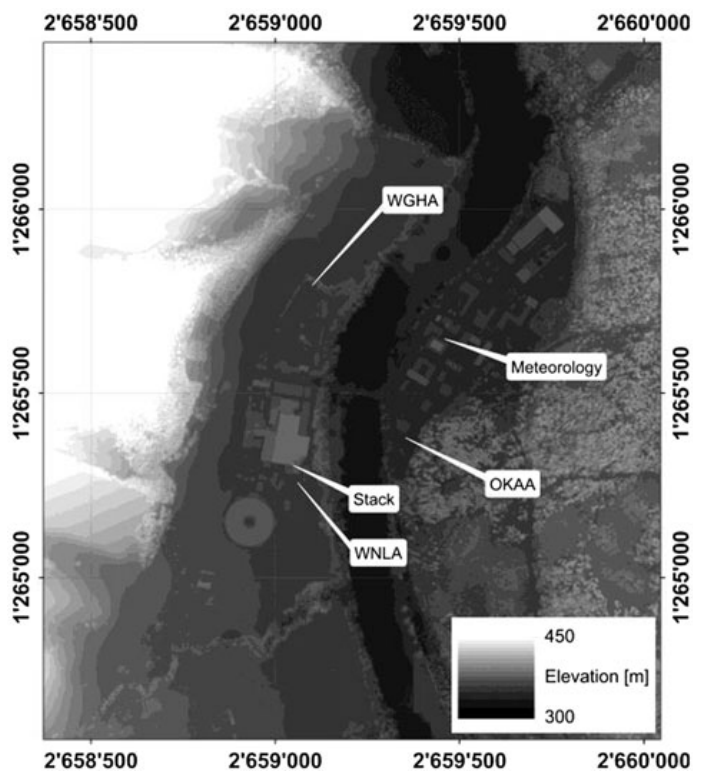

Figure 2. Situation of the three measuring stations WNLA, OKAA and WGHA on an elevation map of the PSI site. DOM (C) 2013 swisstopo (JD100042).

'Meteorology' in Figure 2 during the years 2012 and 2013.

\section{SOURCE TERM}

The emissions of positron emitters from the stack (Figure 2) are monitored routinely for accounting purposes using high-resolution gamma-spectrometry. During full operation of the proton accelerator ${ }^{(2)} 5-7$ $\mathrm{GBq}$ of gaseous positron emitters are released during $10 \mathrm{~min}$. The maintenance shut-down of the accelerator is reflected in a period with no measurable emissions from the stack (Figure 4).

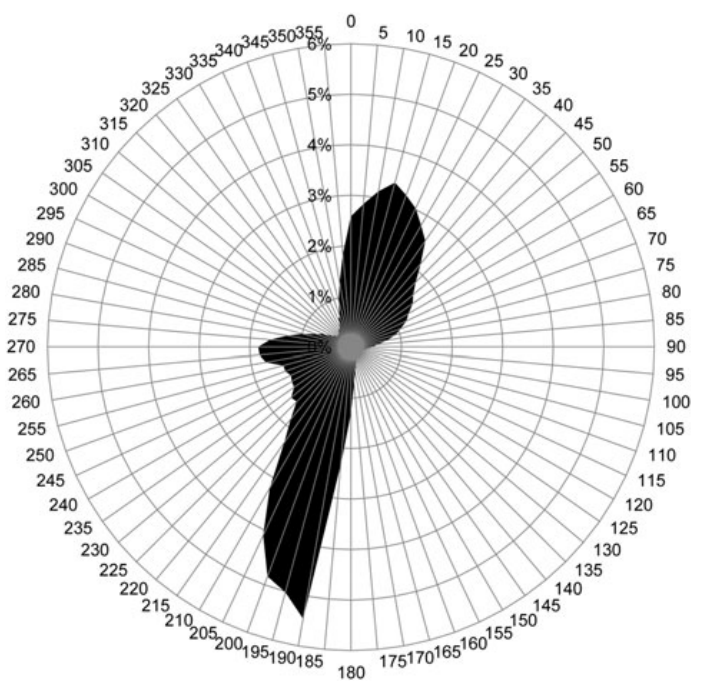

Figure 3. Frequency of wind directions at PSI.

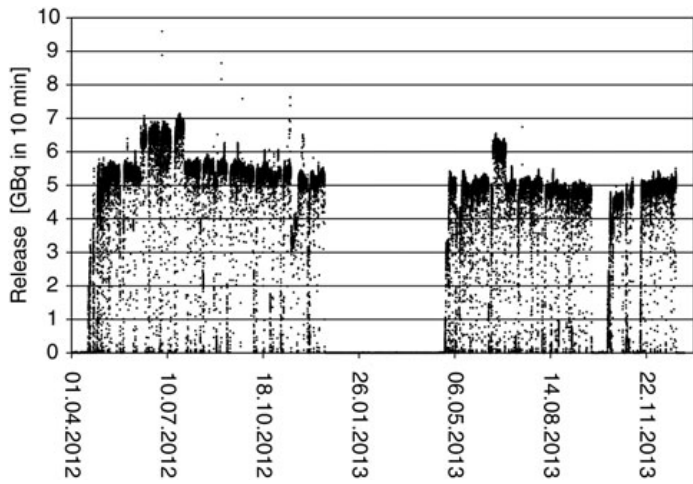

Figure 4. Emission of gaseous positron emitters from the PSI stack in 2012 and 2013.

\section{MMGC-RATIO FREQUENCY DISTRIBUTIONS}

First consistency checks of the signals registered at the measuring stations were performed using frequency distributions of the modified MMGC ratio measured in 2012 and 2013.

\section{All data}

The frequency distributions of all data (Figure 5) show a distinct peak at low MMGC ratios. This peak reflects the baseline value without the influence of positron emitters and radon progeny rain-out. This baseline value is determined by photon emissions of natural radionuclides in the field of view of the measuring station. As the station WNLA is located on the roof of a building, the baseline value is significantly 


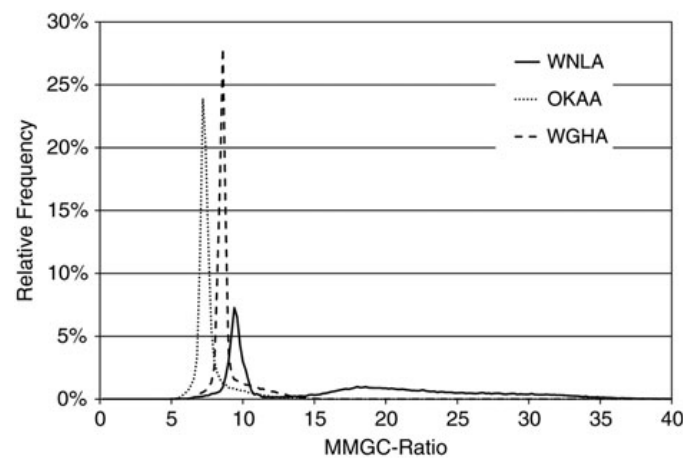

Figure 5. Relative frequency distribution of modified MMGC-ratio values measured in 2012 and 2013.

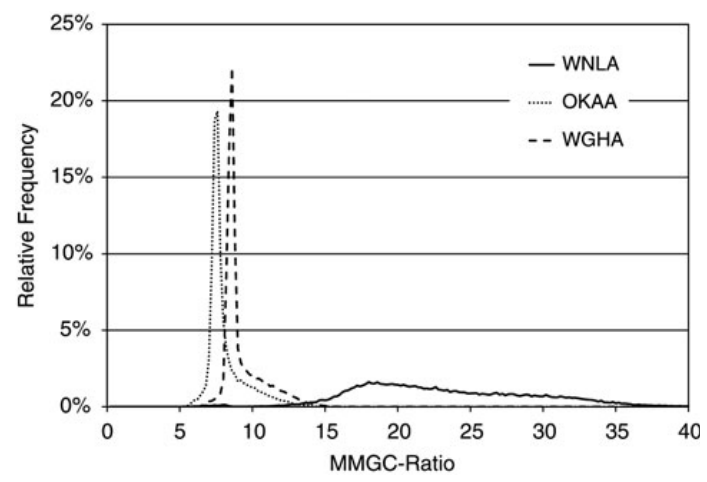

Figure 6. Relative frequency distribution of modified MMGC-ratio values measured in 2012 and 2013 for times with emissions of $>4 \mathrm{GBq}$ in $10 \mathrm{~min}$.

higher compared with the stations OKAA and WGHA, which are located on the ground and have thus a larger signal due to natural radionuclides in the soil.

\section{Reduction according to emissions}

Removing time intervals from the data set with emissions of $<4 \mathrm{GBq}$ in 10 min does not change the shape of the frequency distributions for measuring stations OKAA and WGHA, whereas the baseline peak of measuring station WNLA disappears (Figure 6). Due to the position of station WLNA, the stack itself is located in the field of view of the detector. Thus, emitted positron emitters influence the MMGC ratio partly independent on meteorological conditions.

\section{Further reduction according to wind direction}

The MMGC-ratio data from time intervals with emissions of $>4 \mathrm{GBq}$ in $10 \mathrm{~min}$ are further reduced to values with a wind direction from a sector of $60^{\circ}$

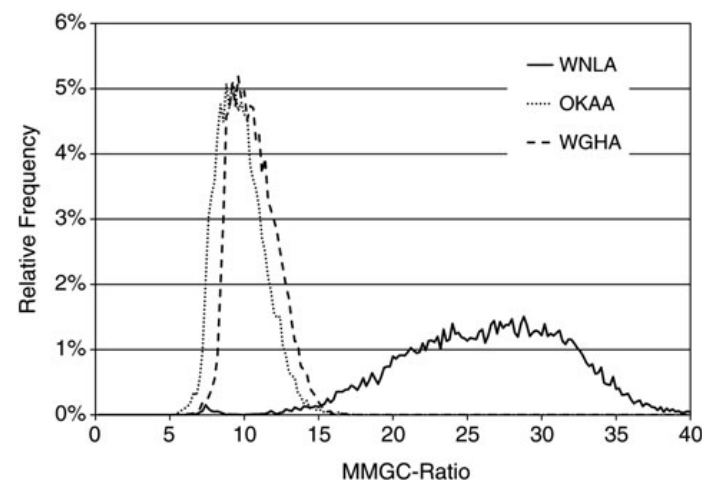

Figure 7. Relative frequency distribution of modified MMGC-ratio values measured in 2012 and 2013 for times with emissions of $>4 \mathrm{GBq}$ in $10 \mathrm{~min}$ and wind directions in a $60^{\circ}$ sector around the direction between measuring station and stack.

around the direction between measurement station and stack. The baseline peak observed for stations OKAA and WGHA vanishes in the according frequency distribution, indicating that all values are influenced by the positron emitters. Alternatively, this means that the baseline peak consists of situations with either no emissions or emissions blown away from the measuring station. The distribution observed for station WNLA is also shifted to higher MMGC ratios, which can be interpreted as the combined effect of positron emitters in the stack and the plume blown into the direction of the measuring station.

\section{SPECIAL CONDITIONS}

The previous section analysed the expected behaviour with the plume transported to the measuring stations and thus increasing the measurement signal. In these cases, modelling with the simple Gaussian plume model used at PSI for accounting purposes will be able to render sufficient dispersion estimates. Nevertheless, these cases represent only $66 \%$ of the measured high modified MMGC ratios at station WNLA, $76 \%$ at station OKAA and $81 \%$ at station WGHA. High modified MMGC ratios were defined values larger than 10 for the measuring stations OKAA and WGHA and larger than 30 for the measuring station WNLA (Figure 7). Even more challenging for dispersion modelling are cases with high modified MMGC ratios and wind blowing from the measuring station towards the stack. A $60^{\circ}$ wind direction sector around the direction between stack and measuring stations was used to represent this condition. With these parameters, $9 \%$ of the high MMGC ratios at station WGHA, $5 \%$ at station WNLA and $1 \%$ at station OKAA were found in the direction opposite to the dispersion direction of 
the Gaussian plume model based on the wind direction measured in a 70-m height.

\section{CONCLUSIONS}

Gaseous positron emitters released from the stack of the accelerator facility of PSI can be detected in the surrounding area with automated gamma-spectrometric measuring stations. The concept of a modified MMGC ratio yields a clear signal associated with the positron emitters while minimising the influence of radon progeny rain-out events. A dependence of the measured MMGC ratios on the emitted activity and wind direction could be demonstrated using frequency distributions of the modified MMGC ratio measured in 2012 and 2013. A significant fraction of high MMGC-ratio values was found associated with dispersion directions (based on measurements of the wind direction in $70 \mathrm{~m}$ above ground) not towards or even against the direction between stack and measuring station. The difficult topography of PSI in the Aare valley with the Aare River flowing right through the institute can be considered as reason for these observations. The micro-climate generated under these conditions leads to a complex wind field, which can invalidate dispersion calculations using a simple Gaussian plume model. The evaluation of an upgrade of the dispersion modelling code used at PSI will include a challenge with the measured data.

\section{FUNDING}

The presented work was funded by the Swiss Nuclear Safety Inspectorate under contract No. 100694 and 100979.

\section{REFERENCES}

1. Schwarz, G. F., Rybach, L. and Klingelé, E. E. Design, calibration, and application of an airborne gamma spectrometer system in Switzerland. Geophysics 62(5), 1369-1378 (1997).

2. Bi, Y. J., Adelmann, A., Dölling, R., Humbel, M., Joho, W., Seidel, M. and Zhang, T. J. Towards quantitative simulations of high power proton cyclotrons. Phys. Rev. STAB 14, 054402 (2011). 